\title{
Optimizing the Polymerization Conditions of Conductive Polypyrrole
}

\author{
Hui Song, Tingxi Li*, Yongqin Han, Yanmin Wang, Chengxiang Zhang, and \\ Qing Wang*
}

\author{
College of Materials Science and Engineering, Shandong University of Science \\ and Technology, Qingdao 266590, China \\ Corresponding author:Tingxi Li and Qing Wang \\ E-mail:litx@sdust.edu.cn,profqwang@163.com
}

\begin{abstract}
Nanostructured polypyrrole (PPy) was successfully prepared via template-free emulsion polymerization method. In this paper, we discuss the influence of polymerization conditions such as the types of doping agent, the reaction time, the reaction temperature, the types of oxidant, and the oxidant-pyrrole molar ratio on the yield and resistance of doped PPy. The results revealed that these factors had an important effect on yield and resistance properties of the doped PPy. When synthesized under the optimal reaction condition at $0{ }^{\circ} \mathrm{C}$, the yield and resistance of the doped PPy were $66 \%$ and $0.12 \Omega$, respectively. In addition, the crystallinity, chemical structure and morphology of the doped nanostructured PPy under the optimal polymerization condition and the undoped PPy were characterized by X-ray diffraction, Fourier transform infrared spectroscopy and scanning electron microscope. The results demonstrated that doped polypyrrole has the morphology of interconnected spherical structure and higher crystallinity.
\end{abstract}

Keywords: chemical structure, resistance, yield, polypyrrole

\section{Introduction}

Since the polyacetylene was first synthesized with unique metal-like properties by Shirakawa et al. and Chiang et al. in 1977, conducting polymers have attracted worldwide attention, due to their attractive features such as surface reactivity, particularly room-temperature sensing property and the wide range of controllable conductivity $[1,2]$. These unconventional properties of an organic material encourage more and more interest numerous other conducting polymers with similar properties were synthesized, such as polypyrrole (PPy), polyaniline (PANI), polythiophene (PTh), and poly (3,4-ethylenedioxythiophene) (PEDOT) etc., were discovered [3,4]. Among various conductive polymers, PPy has been extensively studied because of its extensive applications in the fields of antistatic material, rechargeable batteries, sensors, printing circuit board, stealth material, electrochromic material, drug delivery and others owing to its high electrical conductivity, redox reversibility, good environment stability, good biocompatibility, relatively easy synthesis and low toxicity [5-8].

We all know that PPy can generally be prepared by chemical oxidative-polymerization methods and electrochemical polymerization methods [9]. Both can involve a template during the polymerization of pyrrole so as to obtain polypyrrole nanostructures, the products of these methods are often involved in extra steps for the removal of the template which often destroy PPy nanostructures $[8,10]$. The template-free emulsion polymerization methods provide a number of advantages such as the good solubility in common organic solvents and the easily of preparing a large amount of polymer. Therefore, we considered using template-free emulsion polymerization to synthesize PPy. The most widely accepted polymerization mechanism of pyrrole is the coupling between radical cations [4]. According to the mechanism, in the first step, the oxidation of a pyrrole monomer forms chemically active radical cations of the monomer, with highest charge density at the $\alpha$-position, the coupling between two radical cations occurs, resulting in the formation of 
$\alpha, \alpha$-dimers and then deprotonation produces bipyrrole; in the second step, the bipyrrole is oxidized again and couples with another oxidized segment until completion of the polymerization reaction [4,11]. Scheme 1 displays a schematic illustration of the preparation procedure for polypyrrole materials.

There have numerous studies on preparation different properties polypyrrole. However, the influencing tendency of each factor is unclear and the reason of the effect need to be investigated in detail. Therefore, the purpose of this article is to study the influence of the types of doping agent, the reaction time, the reaction temperature, the types of oxidant, and the oxidant-pyrrole molar ratio on the morphology, structure, yield and resistance of as-synthesized doped PPy. In this article, a template-free emulsion polymerization method was used to synthesize PPy in aqueous solution under different polymerization conditions. And based on the analysis of the different experiments, the optimal synthesis condition was finally obtained. As a result, the 1,5-naphthalene disulfonic acid-doped PPy using $\mathrm{FeCl}_{3}$ as the oxidant at $0{ }^{\circ} \mathrm{C}$ with an inter-connected nanostructure has the highest yield and minimal resistance. The characterization of the doped PPy and the undoped one were compared each other.
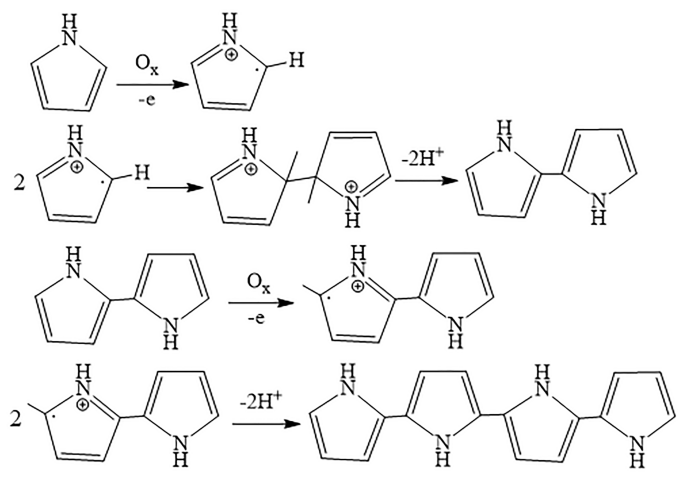

or

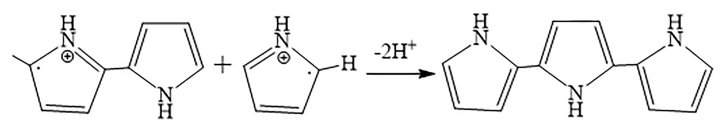

Scheme 1. Schematic illustration of the preparation procedure for polypyrrole.

\section{Experimental}

\subsection{Materials}

Pyrrole (Py) (AR, Chemical Reagent Co. Ltd); ammonium peroxydisulfate (APS) $\left(\left(\mathrm{NH}_{4}\right)_{2} \mathrm{~S}_{2} \mathrm{O}_{8}\right)$ (AR, Tianda Chemical Reagent Factory); hydrochloric acid $(\mathrm{HCl} ; 36.5 \%)$ (AR, Laiyang
Economic \& Technological development zones Fine Chemicals Factory); iron chloride anhydrous $\left(\mathrm{FeCl}_{3}\right), p$-toluenesulfonic acid ( $p$-TA), itaconic acid (IA) and fumaric acid (FA) (AR, Guoyao Group Chemical Reagent Co. Ltd); 1,5-naphthalene disulfonic acid (1,5-NDA) (AR, Xiya Chemical Industry Co. Ltd.).

\subsection{Synthesis of doped PPy}

PPy particles were first prepared in accordance with the literature method. Firstly, $\mathrm{HCl}$ was added to the deionized water to form homogeneous $\mathrm{HCl}$ solution, then, $1 \mathrm{mmol}$ of pyrrole was added to the acid solution and stirred for $30 \mathrm{~min}$. At last, $\left(\mathrm{NH}_{4}\right)_{2} \mathrm{~S}_{2} \mathrm{O}_{8}$ solution was dropwise introduced above solution, and the polymerization reaction was carried on by stirring for $12 \mathrm{~h}$. Subsequently, the product was filtrated, washed with the deionized water until the filtrate was colorless, and finally dried at $60{ }^{\circ} \mathrm{C}$ for $24 \mathrm{~h}$ in vacuum. Based on the single factor analysis method, different influencing polymerization parameters were taken into account including the types of doping agent, the reaction time, the reaction temperature, the oxidant species, and the oxidant-pyrrole molar ratio. Their values varied according to Table 1 in order to obtain PPy with different reaction conditions.

\subsection{Preparation of the undoped PPy}

Undoped PPy prepared under the optimal condition was introduced into $20 \mathrm{~mL}\left(\mathrm{NH}_{4}\right)_{2} \mathrm{~S}_{2} \mathrm{O}_{8}$ solution, oscillated by ultrasonics for $30 \mathrm{~min}$, then filtered and washed with the deionized water until the filtrate was colorless. The undoped PPy was obtained after being dried at $60{ }^{\circ} \mathrm{C}$ in the vacuum baking oven for $24 \mathrm{~h}$.

\subsection{Characterization}

\subsubsection{Yield calculation}

The yield was calculated as the following equation:

$\mathrm{Y}=\mathrm{m}_{2} / \mathrm{m}_{1}$

where $\mathrm{y}$ is the yield, $\mathrm{m}_{2}$ is the weight of PPy, and $\mathrm{m}_{1}$ is the weight of Py monomer.

\subsubsection{Resistance measurement}

To measure the resistance of the doped PPy, the samples were ground and then pressed into a disc with a diameter of $13 \mathrm{~mm}$ under a pressure of $10 \mathrm{MPa}$ for $5 \mathrm{~min}$ using a tabletting machine. Two copper slices were lightly placed on the disc and then connected with an SD2002/3 digital ohmmeter to measure the resistance. 
Table 1. The experiment parameters and corresponding product of doped PPy designed by single factor analysis method.

\begin{tabular}{|c|c|c|c|c|c|c|c|}
\hline $\begin{array}{l}Y_{x} \text { represents } \\
\text { the number of } \\
\text { experiments }\end{array}$ & doping agent & $\begin{array}{l}\text { reaction } \\
\text { time }(\mathrm{h})\end{array}$ & $\begin{array}{l}\text { reaction } \\
\text { temp. }\left({ }^{\circ} \mathrm{C}\right)\end{array}$ & $\begin{array}{l}\text { oxidant } \\
\text { species }\end{array}$ & $\begin{array}{c}\text { molar } \\
\text { ratio }\end{array}$ & $\begin{array}{l}\text { Yield } \\
(\%)\end{array}$ & $\begin{array}{c}\text { Resistance } \\
(\Omega)\end{array}$ \\
\hline $\mathrm{Y}_{1}$ & $\mathrm{HCl}$ & 18 & 0 & $\mathrm{FeCl}_{3}$ & 4 & 39 & 2.6 \\
\hline $\mathrm{Y}_{2}$ & IA & 18 & 0 & $\mathrm{FeCl}_{3}$ & 4 & 37 & 17.0 \\
\hline $\mathrm{Y}_{3}$ & FA & 18 & 0 & $\mathrm{FeCl}_{3}$ & 4 & 27 & 31.4 \\
\hline $\mathrm{Y}_{4}$ & $p$-TA & 18 & 0 & $\mathrm{FeCl}_{3}$ & 4 & 30 & 24.8 \\
\hline $\mathrm{Y}_{5}$ & $1,5-\mathrm{NDA}$ & 18 & 0 & $\mathrm{FeCl}_{3}$ & 4 & 66 & 0.1 \\
\hline $\mathrm{Y}_{6}$ & 1,5-NDA & 18 & 0 & APS & 4 & 39 & 5.0 \\
\hline $\mathrm{Y}_{7}$ & 1,5-NDA & 18 & 0 & $\mathrm{H}_{2} \mathrm{O}_{2}$ & 4 & 10 & 15.6 \\
\hline $\mathrm{Y}_{8}$ & $1,5-\mathrm{NDA}$ & 6 & 0 & $\mathrm{FeCl}_{3}$ & 4 & 28 & 4.3 \\
\hline $\mathrm{Y}_{9}$ & $1,5-\mathrm{NDA}$ & 12 & 0 & $\mathrm{FeCl}_{3}$ & 4 & 50 & 2.3 \\
\hline $\mathrm{Y}_{10}$ & $1,5-\mathrm{NDA}$ & 24 & 0 & $\mathrm{FeCl}_{3}$ & 4 & 41 & 1.0 \\
\hline $\mathrm{Y}_{11}$ & $1,5-\mathrm{NDA}$ & 18 & 25 & $\mathrm{FeCl}_{3}$ & 4 & 23 & 0.3 \\
\hline $\mathrm{Y}_{12}$ & $1,5-\mathrm{NDA}$ & 18 & 50 & $\mathrm{FeCl}_{3}$ & 4 & 37 & 17.0 \\
\hline $\mathrm{Y}_{13}$ & $1,5-\mathrm{NDA}$ & 18 & 75 & $\mathrm{FeCl}_{3}$ & 4 & 27 & 42.3 \\
\hline $\mathrm{Y}_{14}$ & $1,5-\mathrm{NDA}$ & 18 & 0 & $\mathrm{FeCl}_{3}$ & 1 & 11 & 9.1 \\
\hline $\mathrm{Y}_{15}$ & $1,5-\mathrm{NDA}$ & 18 & 0 & $\mathrm{FeCl}_{3}$ & 2 & 18 & 7.2 \\
\hline $\mathrm{Y}_{16}$ & $1,5-\mathrm{NDA}$ & 18 & 0 & $\mathrm{FeCl}_{3}$ & 3 & 25 & 4.6 \\
\hline $\mathrm{Y}_{17}$ & null & 18 & 0 & $\mathrm{FeCl}_{3}$ & 4 & 12 & 34.0 \\
\hline
\end{tabular}

\subsubsection{X-ray diffraction (XRD) measurement}

The undoped PPy and the doped PPy prepared in the optimal condition were placed in the sample cell. X-ray diffraction (XRD) experiments were carried out on Rigaku Dmax 2500 X-ray diffractometer (Japan Science Analysis Instrument Factory) in the range of $4-80^{\circ}$.

\subsubsection{Infrared spectrum measurement}

PPy was ground with $\mathrm{KBr}$ and pressed into a thin disc under the pressure of $10 \mathrm{MPa}$. Fourier transform infrared (FT-IR) spectra were recorded with a Nicolet 380 Fourier transformation infrared spectrometer (Thermo Fisher Scientific Company) in the region of $4000-450 \mathrm{~cm}^{-1}$.

\subsubsection{Scanning electron microprobe}

The morphology of PPy was examined using a scanning electron microscope (SEM, Nova Nano
SEM450, FEI) working at a voltage of $20 \mathrm{kV}$.

\section{Results and discussions}

3.1. Yield and resistance

3.1.1. Resistance and yield of doped PPy with different oxidants and dopants

According to Table 1, we can see that the doped PPy using 1,5-NDA as dopant, anhydrous $\mathrm{FeCl}_{3}$ as oxidant has the highest yield of $66 \%$ and the smallest resistance of $0.12 \Omega$. The possible reasons are as follows: in the same molar mass, the numbers of $\mathrm{H}^{+}$ion in 1,5-NDA are more than that of other acids. Therefore, the numbers of dipole on the polymer chains are more than that of other acids doped PPy and the main part of carriers are polarons. The fermi energy changed due to the increase of the carrier concentration, the energy gap between valence band and conduction band is diminished and hence the mobilities of carriers are 
highly improved because of the carriers are easily transmitted to the empty orbit [5]. During the reaction, the $\mathrm{Fe}^{3+}$ ions in $\mathrm{FeCl}_{3}$ are transformed into $\mathrm{Fe}^{2+}$ ions, transient metal ions such as $\mathrm{Fe}^{2+}$ serves as the dopant anion for the PPy to improve the conductivity of doped-PPy [12].

\subsubsection{Resistance and yield of doped PPy with} different reaction times

Figure 1 represents the yield and resistance of the doped PPy under different reaction times. As shown in Fig. 1, the yield firstly increases and then decreases along with the increase of reaction time, on the contrary, the resistance increases after the first decreases. That is to say, the conductivity of the doped PPy is increases first and then decreases. The possible reasons are as follows: When the reaction time is very short, the doped PPy lack the conducting channel length because of small molecular weight of PPy and low polymerization degree, this results in very low conductivity of doped PPy [13]. Meanwhile, a large number of oligomers with small molecules occur when the reaction time are too low, so the yield of PPy is also very low. But with the increase of the polymerization time, the molecular weight of conjugated PPy chain increases and the length of the arrangement of PPy conjugated chain increases, so the PPy has better yield. When the reaction time at about $18 \mathrm{~h}$, the system has the largest carrier mobility in the big $\pi$ conjugate system and hence the doped PPy has the maximum conductivity; However, when the reaction time continuously increases, the system may have some side reactions (chain transfer and the peroxidation of Py rings), and the regularity and conjugated degree of PPy chains decline, therefore, the conductivity of PPy decrease [5]. At the same time, the long reaction time brings about the polymer over oxidation and generates the by-products, so the yields of PPy also decrease.

3.1.3. Resistance and yield of doped PPy with different reaction temperatures

Figure 2 is the yield and resistance of doped PPy with the different reaction temperatures. From the figure, it can reveal that the yield decreases with the increases of the reaction temperature and the resistance of doped PPy increases with the increases of the temperature, in other words, the conductivity of doped PPy declines with reaction temperature increases. This phenomenon can be explained as follows: in the higher temperature, the arrangement

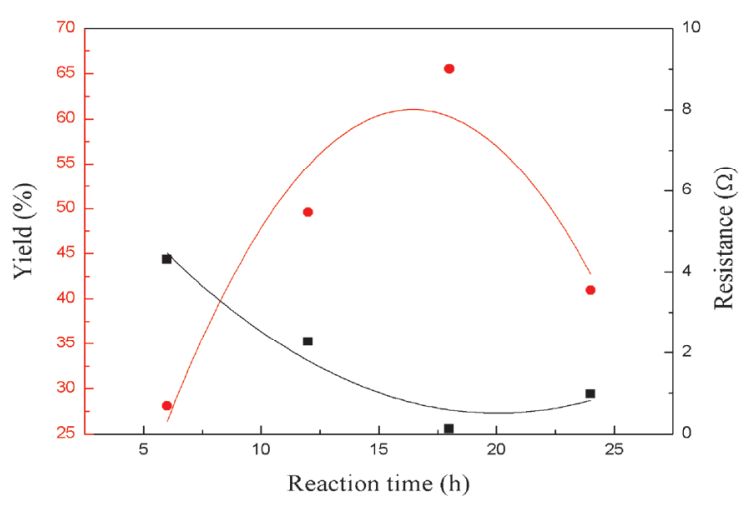

Fig. 1. Yield and resistance of doped PPy synthesized under different reaction times.

of PPy chains is disordered, the conjugated degree and regularity of PPy chains decrease, and hence resistance of polymer increase. On the contrary, the lower reactive temperature is, the fewer the structural defects on PPy chains are, the more ordered the arrangement of polymer chains is, the higher the mobility of carrier are, and the better the conductivity of polypyrrole are [5]. The polymer chains have perfect yield due to the PPy has more ordered arrangement.

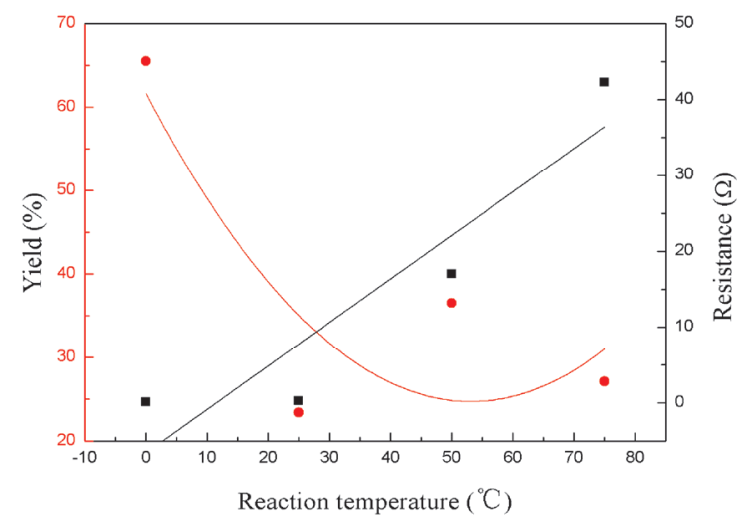

Fig. 2. Yield and resistance of doped PPy synthesized under different reaction temperatures.

3.1.4. Resistance and yield of doped PPy with different ratios of $\mathrm{n}\left(\mathrm{FeCl}_{3}\right) / \mathrm{n}(\mathrm{Py})$

The yield and resistance of the doped PPy with different molar ratios of $n\left(\mathrm{FeCl}_{3}\right) / \mathrm{n}(\mathrm{Py})$ are shown in Fig. 3. It can be seen that the yield of doped PPy increases, but the resistance of doped PPy decreases as $\mathrm{n}\left(\mathrm{FeCl}_{3}\right) / \mathrm{n}(\mathrm{Py})$ increases, and that is to say, the conductivity of PPy increases with $\mathrm{n}\left(\mathrm{FeCl}_{3}\right) / \mathrm{n}(\mathrm{Py})$ increases. The possible explanations are as follows: with the increase of the oxidant amount in the system, the Py gradually polymerize into the macromolecules and the polymerization degree of PPy significantly increase, here the regularity of PPy chain reaches its optimal form, and hence the 
sample presents better yield and favorable conductivity [13]. In a word, the 1,5-naphthalene disulfonic acid-doped PPy using $\mathrm{FeCl}_{3}$ as the oxidant and with $\mathrm{n}\left(\mathrm{FeCl}_{3}\right) / \mathrm{n}(\mathrm{Py})=4$ at $0{ }^{\circ} \mathrm{C}$ for $18 \mathrm{~h}$ has better performance of yield and electrical conductivity.

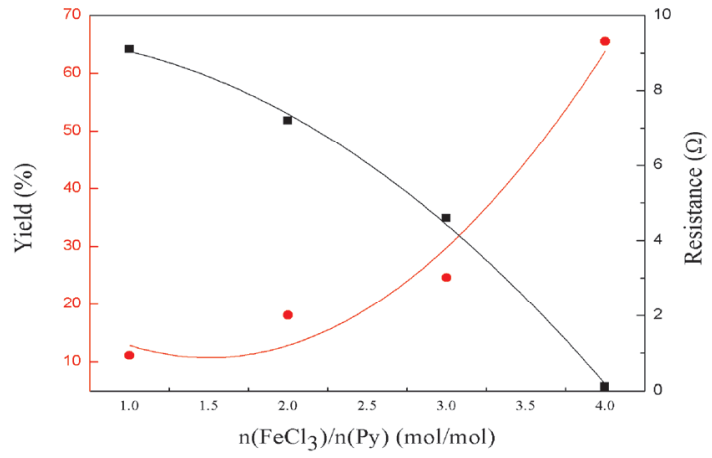

Fig. 3. Yield and resistance of doped PPy synthesized under different ratios of $\mathrm{n}\left(\mathrm{FeCl}_{3}\right) / \mathrm{n}(\mathrm{Py})$.

\subsection{Chemical structure}

Figure 4 shows the FTIR spectra of the PPy synthesized with different dopants in the range of $4000-450 \mathrm{~cm}^{-1}$. For PPy, the band observed at $3410-3440 \mathrm{~cm}^{-1}$ is assigned to the $-\mathrm{OH}$ vibration band coming from water; the bands at 1550 and $1450 \mathrm{~cm}^{-1}$ were attributed to stretching vibrations of the pyrrole ring e.g. the combination of $\mathrm{C}=\mathrm{C}$ and $\mathrm{C}-\mathrm{C}$ stretching vibrations; furthermore, the bands at 1050 and $1200 \mathrm{~cm}^{-1}$ can be ascribed to $\mathrm{C}-\mathrm{H}$ deformation vibrations and $\mathrm{C}-\mathrm{N}$ stretching vibrations, respectively; and the band at $922 \mathrm{~cm}^{-1}$ is assigned to $\mathrm{C}=\mathrm{C}$ in-plane bending vibrations of the pyrrole ring [14-16]. As seen in Fig. 4, all the main characteristic peaks of PPy are similar from each other.

However, a slight difference in the intensity and position of these peaks could be found in the PPy synthesized under different reaction dopants. In comparison with undoped PPy, the intensity and position of characteristic peak relating to stretching vibration of the pyrrole rings for the doped PPy have changed, indicating that the changes of chemical environment due to the existence of different dopants in the doped PPy. The decreasing intensity of the peak at $1550,1200,922 \mathrm{~cm}^{-1}$ may indicate that the addition of dopant adds the charge delocalization of the $\mathrm{C}=\mathrm{C}, \mathrm{C}-\mathrm{N}$ in the $\mathrm{PPy}$ backbone.

\subsection{Crystalline structure}

Figure 5 shows XRD patterns for the PPy synthesized under optimum conditions $\left(0^{\circ} \mathrm{C}, 18 \mathrm{~h}\right.$,

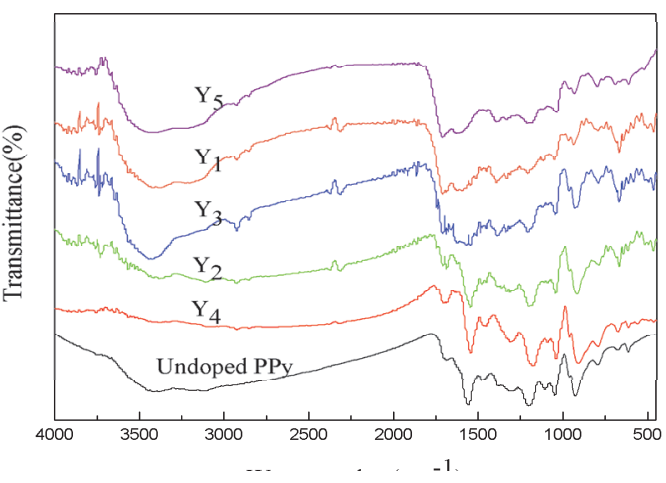

Fig. 4. FTIR spectra of PPy synthesized with different dopants.

doped with 1,5-NDA, oxidation with $\mathrm{FeCl}_{3}$, $\left.\mathrm{n}\left(\mathrm{FeCl}_{3}\right) / \mathrm{n}(\mathrm{Py})=4\right)$ and the undoped PPy. Some periodicity in the structure for semicrystalline conjugated polymers could be observed. It can be observed that all samples of PPy show a broad diffraction peak with an amorphous structure at about $2 \theta=20-25^{\circ}$, this is due to $\pi-\pi^{*}$ interactions of partial PPy chains, and it is in good agreement with the literature [13]. However, an increase in the peak intensity of PPy occurred when PPy was doped by the 1,5-NDA, and what is more, a relatively obvious small broad peak at $11.0^{\circ}$ has disappeared, which implied that a large degree of orientation for PPy chains existed in the doped PPy, that is to say, the crystallinity of PPy increased when PPy was doped.

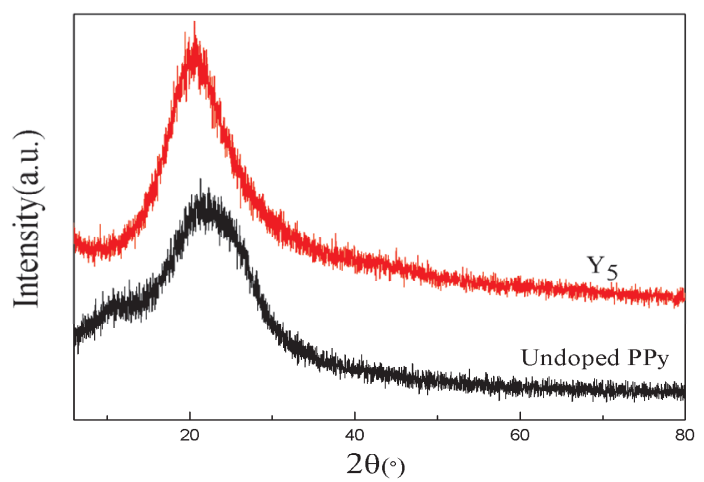

Fig. 5. XRD patterns of PPy synthesized under optimum conditions and undoped PPy.

\subsection{Morphology analysis}

The SEM images of the PPy prepared at optimum conditions $\left(0{ }^{\circ} \mathrm{C}, 18 \mathrm{~h}\right.$, doped with 1,5-NDA, oxidation with $\left.\mathrm{FeCl}_{3}, \mathrm{n}\left(\mathrm{FeCl}_{3}\right) / \mathrm{n}(\mathrm{Py})=4\right)$ and the undoped PPy are shown in Fig. 6. From the micrographs, one can see that the surface morphology of PPy changes from agglomerated spherical particles to inter-connected PPy particles 
as the addition of the 1,5-NDA. These inter-connected nanospheres have an important effect on conductivity for samples. This improvement should also be related to the charge-transfer process between the inter-connected nanospheres, which can cause an increase in the conductivity of the doped-PPy.

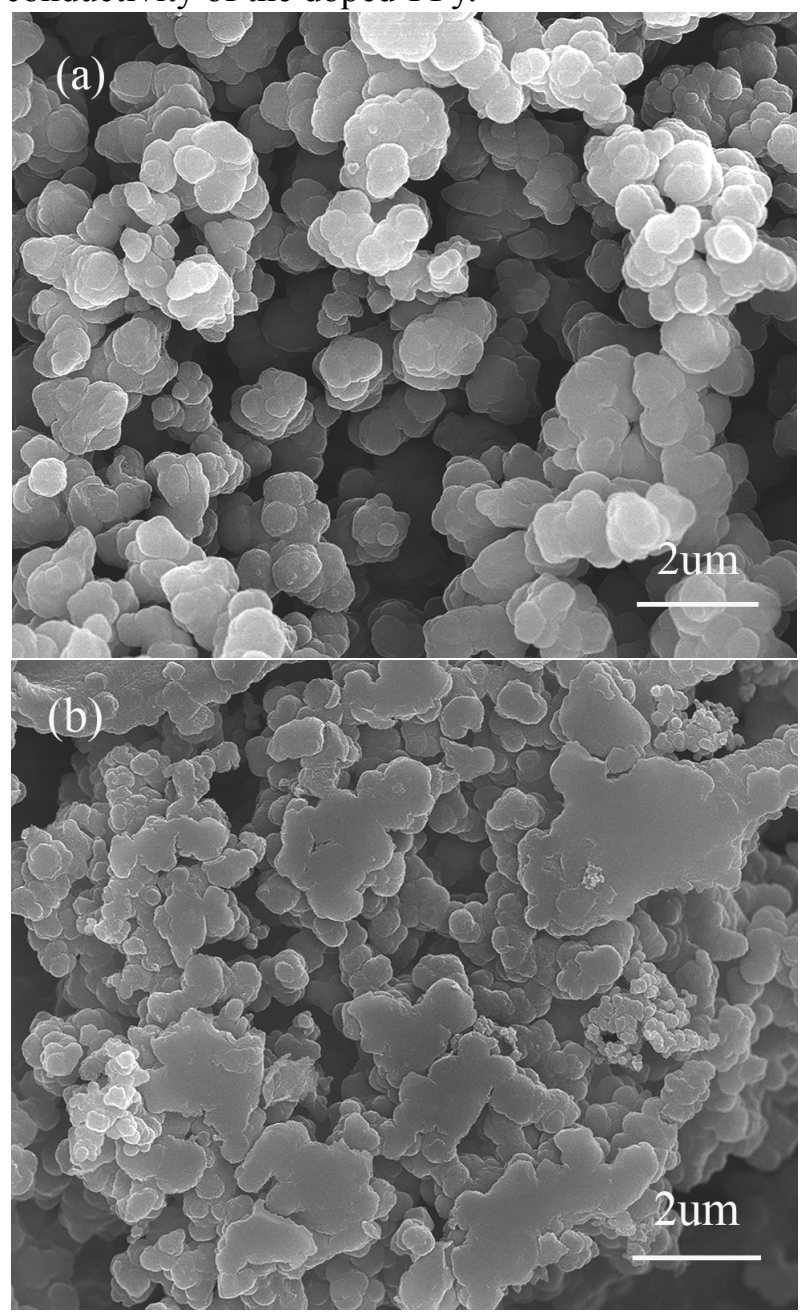

Fig. 6. The SEM images of (a) undoped PPy and (b) the PPy prepared at optimum conditions.

\section{Conclusions}

The PPy samples with different reaction conditions are successfully synthesized by template-free emulsion polymerization method. Different dopants, oxidants, oxidant-pyrrole ratios, reaction times, reaction temperatures greatly affect the yield, resistance, chemical structure, and surface morphology of the doped PPy. The experimental results show that the PPy obtained by doping with 1,5-NDA and oxidation with $\mathrm{FeCl}_{3}$, with $\mathrm{n}\left(\mathrm{FeCl}_{3}\right) / \mathrm{n}(\mathrm{Py})=4$ at $0{ }^{\circ} \mathrm{C}$ for $18 \mathrm{~h}$ had better performance of electrical conductivity and yield. The entrance of 1,5-NDA into PPy backbone improves its crystallinity and conductivity. The electrical and yield of the PPy can be tuned by controlling of reaction condition, which is of great importance to apply in antistatic coatings, drug delivery systems, batteries, sensors and so on.

\section{Acknowledgements}

This work was supported by Taishan Scholarship Project of Shandong Province, China (No. tshw20130956).

\section{References}

1. A. J. Heeger, Angew. Chem. Int. Ed., 40 (2001) 2591.

2. Y. M. Wang, K. Chen, T. X. Li, H. M. Li, R. C. Zeng, R. L. Zhang, Y. J. Gu, J. X. Ding, and H. Q. Liu, Synth. Met., 198 (2014) 293.

3. Z. B. Huang, G. F. Yin, X. M. Liao, and J. W. Gu, Front. Mater. Sci., 8 (2014) 39.

4. A. K. Minkstimiene, V. Mazeiko, A. Ramanaviciene, and A. Ramanavicius, Colloids Surf A: Physicochem. Eng. Aspects., 483 (2015) 224.

5. B. Hao, L. C. Li, Y. P. Wang, H. S. Qian, G. X. Tong, H. F. Chen, and K. Y. Chen, J. Appl. Polym. Sci., 127 (2013) 4273.

6. Y. S. Qiao, L. Z. Shen, M. X. Wu, Y. Guo, and S. M. Meng, Mater. Lett., 126 (2014) 185.

7. X. H. Liu, H. Y. Wu, F. L. Ren, G. Z. Qiu and M. T. Tang, Mater. Chem. Phys., 109 (2008) 5.

8. L. Benhaddad, M.C. Bernard, C. Deslouis, L. Makhloufi, B. Messaoudi, A. Pailleret, and H. Takenouti, Synth. Met., 175 (2013) 192.

9. J. Liu and M. X. Wan, J. Mater. Chem., 11 (2001) 404.

10. Y. Y. Wang, T. Q. Liu, and W. W. Xu, Chem. Res. Chin. Univ., 29 (2013) 607.

11. F. Wolfart, D. P. Dubal, M. Vidotti, R. Holze, and P. G. Romero, J. Solid State Electrochem., 20 (2016) 901.

12. F. Tavoli and N. Alizadeh, J. Electroanal. Chem., 746 (2015) 39.

13. Y. M. Wang, K. Chen, T. X. Li, and H. M. Li, High Perform. Polym., 28 (2016) 322.

14. D. P. Dubal, S. H. Lee, J. G. Kim, W. B. Kim, and C. D. Lokhande, J. Mater. Chem., 22 (2012) 3044.

15. B. L. Liang, Z. Y. Qin, J. Y. Zhao, Y. Zhang, Z. Zhou, and Y. Q. Lu, J. Mater. Chem. A., 2 (2014) 2129.

16. A. Stirke, R. M. Apetrei, M. Kirsnyte, L. Dedelaite, V. Bondarenka, V. Jasulaitiene, M. Pucetaite, A. Selskis, G. Carac, G. Bahrim, and A. Ramanavicius, Polymer, 84 (2016) 99. 